\title{
The effectiveness of interactive mobile health technologies in improving antenatal care service utilization in Dodoma region, Tanzania: A quasi experimental study
}

\section{THERESIA JOHN MASOI ( $\square$ jtheresia2008@yahoo.com )}

The University of Dodoma College of Health Sciences https://orcid.org/0000-0003-1700-7842

\section{Stephen M. Kibusi}

The University of Dodoma College of Health Sciences

\section{Alex Ernest}

The University of Dodoma College of Health Sciences

Athanase G. Lilungulu

The University of Dodoma College of Health Sciences

\section{Research}

Keywords: Mobile health technology, Antenatal care, maternal and child health, health information systems, Service utilization

Posted Date: June 10th, 2020

DOI: https://doi.org/10.21203/rs.3.rs-34094/v1

License: (1) This work is licensed under a Creative Commons Attribution 4.0 International License.

Read Full License 


\section{Abstract}

Background Antenatal care provides a platform for important health care functions during pregnancy, including health promotion, screening, and diagnosis and disease prevention. Timely and appropriate utilization of antenatal care can prevent complications and ensure better maternal and newborn health care. The aim of this study was to assess the effectiveness of interactive mobile health technologies in improving antenatal care service utilization in Dodoma region, Tanzania Methods A controlled quasiexperimental study was carried. Random selection of participants was employed to achieve a sample size of 450 pregnant women (Intervention=150 and Control=300). Interventions were matched to controls by gravidity and gestational age at a ratio of 1:2.The intervention group was enrolled in an interactive mobile messaging system and received health education messages. The control group continued with the standard antenatal care services being offered in local clinics. Pregnant women were followed from their initial visit to the point of delivery. Independent two-sample T-tests and logistic regression were used

to test the effect of the intervention. Results The mean age of the participants was found to be 25.6 years with a range of 16 to 48 years. $77.3 \%$ of participants in the intervention group utilize ANC services as compared to $57.7 \%$ in the control group. The mean score was $(M=2.77, S D 0.420)$ in the intervention group against $(M=2.58, S D=0.495)$ in the control with $(t=4.172, P<0.01)$ at $95 \% \mathrm{Cl}$. Interactive $S M S$ alert system,was observed to be effective on improving Antenatal care service utilization $(A O R=2.164, P<0.05$, $95 \% \mathrm{Cl}=1.351-3.466)$ as compared to conventional Antenatal care health education given in our health facilities. Conclusion The Interactive mobile health technologies used in this study has the potential of empowering pregnant women through greater access to information and in improving antenatal care service utilization in our setting.

\section{Plain English Summary}

Health care services during pregnancy and childbirth and after delivery are important for the survival and well-being of both the mother and the newborn. Timely and appropriate utilization of antenatal care services can prevent complications and ensure better maternal and newborn outcome. This study assessed the effectiveness of interactive mobile health technologies in improving antenatal care service utilization in Dodoma region, Tanzania

A total of 450 pregnant women were randomly selected and involved in the study, among them 150 were given the intervention and the remained 300 received the routine antenatal care services being offered in the local clinics and saved as control group. The intervention group was enrolled in an interactive mobile messaging system and received health education messages. Pregnant women were followed from their first visit to the point of delivery.

The average age of the participants was found to be 25.6 years ranging 16 to 48 years. $77.3 \%$ of participants in the intervention group utilize antenatal services as compared to $57.7 \%$ in the control group. The Interactive SMS alert system, was also observed to be effective on improving Antenatal care 
service utilization as participants in the intervention group were able to utilize the services two times more as compared to the control group.

As from the above findings, the Interactive mobile health technologies used in this study has the potential to empower pregnant women through greater access to information and in improving antenatal care service utilization in our setting.

\section{Background}

Health care services during pregnancy, childbirth and after delivery are important for the survival and wellbeing of both the mother and the newborn. Identification and management of antenatal risk factors at early stage are important for positive maternal and newborn outcomes. Timely and appropriate utilization of antenatal care can prevent complications and ensure better maternal and newborn health care (1). The World Health Organization (WHO) has recommended three core health sector strategies for reducing maternal and early neonatal deaths namely comprehensive reproductive health care, skilled care for all pregnant women especially during delivery and emergency obstetric care for all women and infants with life-threatening complications (World Health Organization, 2016) .

Antenatal care (ANC) being one of the package of reproductive health care, provides a platform for important health care functions during pregnancy including health promotion, screening, diagnosis and disease prevention (World Health Organization, 2016) Antenatal care also provides the opportunity to communicate with and support women, families, and communities at a critical time in the course of a woman's life (3).

Despite of a number of global and national efforts to improve women's health, the death of women during pregnancy, childbirth and after childbirth remains an unresolved challenge in many developing countries, including Tanzania (4).

Almost two decades since the initiation of the Safe Motherhood Initiative, maternal mortality is still soaring high in many developing countries. About 830 women die from pregnancy or childbirth related complications around the world every day (5). Tanzania is one of the ten countries contributing to $61 \%$ and $66 \%$ of the global total maternal and newborn deaths, respectively (6).

The estimated MMR in the 2015-16 Tanzania Demographic and Health Survey (TDHS- MIS) report was $556 / 100000$ live births which is higher compared to the 2010 TDHS report which was 454/100000 live births (7). Many complex factors contribute to this such as low level of education, knowledge and economic power of women to make informed reproductive health decisions.

Increasing the utilization of maternal health care services is an important strategy to reduce preventable maternal morbidity and mortality. Each year, roughly a third of global maternal deaths are due to inadequate care during pregnancy. Antenatal care visits are ideal time to advice women and their families on essential pregnancy care and develop a birth plan and complications readiness. These approaches 
improve outcomes for women and may also reduce stillbirths and neonatal deaths. Improving maternal and neonatal health outcomes involves the provision and uptake of antenatal services that are timely (first visit during the first three months of pregnancy), sufficient (at least four antenatal visits) and adequate with appropriate content (8).

A study done on antenatal care estimated that worldwide, only $70 \%$ of pregnant women receive any ANC whereas in industrialized countries more than $95 \%$ of pregnant women receive ANC (5).

In Tanzania, according to the 2015/2016 Demographic and Health Survey, twenty-four percent of pregnant women started antenatal care in their first trimester, and half $(51 \%)$ had four or more ANC visits as recommended. In the (2004/05) TDHS report, $94 \%$ of pregnant women had at least one antenatal care (ANC) visit and $62 \%$ of women had four or more ANC visits, the median gestational age of pregnant women in their first ANC visit is 5.4 months (7).

In order to prevent adverse pregnancy outcome worldwide, interventions should be targeted for all pregnant women attending antenatal care service and during childbirth. Antenatal care should be carried out with well supported and effective technologies for comprehensive monitoring and prompt communication when complications or risks are detected.

There is scarce published data on use of text messaging with cell phones (SMS) as a vehicle to increasing health knowledge and potentially change of behavior during pregnancy (9). Little evidence exists regarding the different types of mobile health applications that can be used in low-resource settings as well (10).

This study aimed at assessing the effectiveness of interactive mobile health technologies in improving antenatal care service utilization in Dodoma region, Tanzania.

\section{Methods}

\section{Study setting}

This study was carried out at Dodoma Municipal for both the intervention group and control group from January to November, 2018. Dodoma Municipality is found in Dodoma Urban. The region is one of Tanzania's 30 administrative regions as well as a Capital city of the country. It lies centrally in the easterncentral part of the country; it is about 300 miles $(480 \mathrm{~km})$ of the coast. Dodoma Urban District is one of the seven districts of the Dodoma region of Tanzania. It is bordered to the west by the Bahi district, and to the east by Chamwino district. According to the 2012 Tanzania national census, the population of Dodoma urban district was 410,956 and the area of 2,576 square kilometers (11). Dodoma is one of the regions with the highest maternal mortality rates in Tanzania as in 2012, Dodoma ranked the ninth high burdened region with a maternal mortality rate of 512/100,000 live births (12) . 
Within the municipal, there are two major public hospitals; the Makole health center which serves as the main antenatal care facility and the Dodoma regional referral hospital which caters for all deliveries for high-risk mothers. In this study, the interactive mobile health was developed and pregnant mothers Attending Antenatal care Services at Makole Health center and Chamwino Dispensary were followed and receive text messages regarding their pregnancy. Control group were taken from other facilities offering $\mathrm{RCH}$ and delivery services in Dodoma Municipal which were not selected for the intervention and included Hombolo Health center, mkonze health centre and St.Gemma hospital.

\section{Study Design}

The study was a Quasi-experimental study with control group. The intervention group was enrolled in the Interactive system and received Health education messages pertaining to their pregnancy, whereas control group went on with the normal Standard ANC service being offered in our ANC local clinics.

\section{Study Population}

All pregnant women who started their first antenatal visit below the first twenty weeks .Controls were pregnant who used the current antenatal care assessment modality as per Tanzania guideline that also started their first visit below the first 20 weeks. Controls were matched to the intervention group by age group, education level, gravidity Parity and gestation age.

\section{Sampling Technique}

A purposive sampling method was used to select healthcare facilities offering ANC and delivery care services in Dodoma Municipal. Purposeful sampling was employed to ensure that data came from all levels of the maternal services referral system in the region. Systematic random sampling method was used to select participants for both the intervention and control groups. Every third pregnant woman among those who met the criteria in a given day and agreed to participate in the study was selected until the required number of sample was obtained.

\section{Sample Size}

The sample size for the Intervention and Control group was obtained by using the formula for comparing two independent samples(Intervention group against control group), and using proportion women attending Four visit or more at baseline was $51 \%$ and after intervention it was $63 \%$ as per (Ekirapa, Muhumuza, Tetui, \& George, 2017), A Quasi-experiment that was done in Rural Uganda on Maternal Health Service utilization and Newborn care. Standard normal deviation of 1.96 at $95 \%$ confidence interval $(\mathrm{Cl})$ with $5 \%$ attrition rate. So, the minimum sample size was 142 plus $5 \%$ Attrition $=150$. The ratio 
of the Intervention group to control was 1:2, so controls were 300 . The total sample size in this study was 450 pregnant women.

\section{Inclusion and exclusion criteria}

All pregnant women who started their ANC first visit below 20 weeks, attending ANC and planning to deliver in Dodoma Municipal and who owned phones and consented to participate were considered for the study. Pregnant women who were receiving pregnancy-related health text SMS from other sources through their mobile phones and those who meet the inclusion criteria and refused to participate were excluded from the study.

\section{Measurements Of Variables}

\section{Antenatal care service utilization:}

Adequate antenatal care service utilization was measured by:

1. ANC care provided by skilled health personnel (a nurse or a doctor)

2. Sufficient number of ANC visits (4 or more visits during pregnancy),

3. Appropriate ANC content provided (Included at least 13 out of 15 of the recommended basic care procedures or contents). The sample was divided into two outcome categories: Received adequate antenatal care (delivered by skilled health personnel, Sufficient and with appropriate content).received inadequate antenatal care (services which did not fully comply with the above criteria). Adequate ANC care corresponded to receiving thirteen out of fifteen basic ANC This method of scoring has been previously used in Mexico to measure the adequacy of antenatal health It was adopted and modified to fit the Tanzania content (8).

\section{Components of antenatal care offered in Tanzania include}

Blood test for hemoglobin level, urine test for protein and sugar, obstetric exam, blood pressure measurement, maternal weight/height, rapid syphilis test, blood type and Rh factor testing, tetanus toxoid vaccine, iron/folic acid supplementation, antimalaria prophylaxis and client health education and counseling as well as HIV/AIDS testing, one ultrasound scan in the first 24 weeks of pregnancy. Currently, all the information are being recorded on the antenatal card ( $\mathrm{RCH} 4)$.

\section{Research Instrument/tool}

Semi-structured questionnaire (with both closed and open-ended questions) was developed to be interviewer-administered. This ensured that those unable to read and write could fully participate and also to ensure optimal capturing of all the needed information. The questionnaire included questions on sociodemographic characteristics, utilization of antenatal care services. The questionnaire was first developed 
in English and then translated later to Kiswahili which is the national language of Tanzania and the language used by the study population. The questionnaire was adopted and modified from Jhpiego and modified to fit the Tanzanian context (14) also from Tanzania Demographic and Health Survey 2015/2016 and from Nepal Demographic and Health Survey (15).

\section{Overview Of The System}

Interactive mobile health system is a computerized system that ensures the provision of reproductive health and communication between pregnant woman and the medical practitioners. The system started working in January, 2018 whereby pregnant women who started their first antenatal visit below 20 weeks were recruited and enrolled at Makole Health Centre and Chamwino Dispensary. The participants were followed until delivery. The system tracks every visit diagnosis and assembles them to give the general health overview of a woman in each trimester of the visit. The system also included an SMS Module where pregnant mothers were notified with SMS texts about when to come for the next visit and were also given health tips and were also able to call and text back for clarification when need arises .See the diagram below

\section{Data Processing And Analysis}

In this study, data was analyzed by using the Statistical Product for Service Solutions (SPSS) software program version 21 . Before conducting the analysis, the error checking (data cleaning) was performed by using Frequency distribution tables to see if all the data were entered correctly. Each variable was manually cross-checked to ensure validity and reliability of the findings. Scores that were out of range were corrected to avoid distortion of the statistical analysis.

Descriptive analysis was used to analyze participant's characteristics to determine the frequencies and percentages of their distributions between the two groups. Chi-square test was employed to analyze all categorical data to see their distributions between the two groups and to establish the relationship between the categorical variables and the outcome variables. Independent two-sample T-test was used to compare the mean scores and establish any effect of the intervention between the two groups. Logistic regression analysis was also used to establish the association between the interactive mobile health system and ANC service utilization. A confidence interval of $95 \%$ with the margin of error $5 \%(0.05)$ were used as statistical measure of significance $(<0.05$ was regarded as significant while $>0.05$ not significant).

\section{Results}

\section{Social demographic characteristics of the participants $(\mathbf{N}=$ 450)}


A total of 450 (intervention group150 pregnant/postnatal women and 300 postnatal women as control group) were recruited and participated in this study. The mean age of respondents in the entire sample was 25.6 years $(S D=6.1)$ with a minimum age of 16 years and maximum age of 48 years. As shown in Table 1 below, the most prominent age group ranged between 20-34 years. There was no significant different in age distribution between the two groups with $(p=0.196)$

On top of that, more than half of the participant, $54.7 \%(n=82)$ in the intervention group against $60.7 \%(n$ $=182)$ in the control group had primary school education level and few with college/university education $10.6 \%(n=16)$ in the intervention group and $7.6 \%(n=23)$ in the control. There was no significant differences in education level between the two groups with $(p=0.381)$. Out of 450 respondents, $78.4 \%$ ( $n$ $=353$ ) were currently in marital union (married/cohabiting). Other results are as shown in Table 1 below.

Table 1

Social demographic characteristics of the participants $(N=450)$

\begin{tabular}{|c|c|c|c|c|c|c|c|}
\hline Variable & \multicolumn{2}{|c|}{ Intervention } & \multicolumn{2}{|c|}{ Control } & \multicolumn{2}{|c|}{ Total/ 450} & \multirow[t]{3}{*}{ P-value } \\
\hline & $\mathrm{n}$ & $\%$ & $\mathrm{n}$ & $\%$ & $\mathrm{n}$ & $\%$ & \\
\hline & & & & & & 3.256 & \\
\hline$<20 \mathrm{yrs}$ & 21 & 14.0 & 61 & 20.3 & 82 & 18.2 & \\
\hline $20-34$ yrs & 111 & 74.0 & 212 & 70.7 & 323 & 71.8 & 0.196 \\
\hline$\geq 35$ yrs & 18 & 12.0 & 27 & 9.0 & 45 & 10.0 & \\
\hline \multicolumn{8}{|l|}{ Education status } \\
\hline Primary school & 82 & 54.7 & 182 & 60.7 & 264 & 58.7 & \\
\hline Secondary school & 52 & 34.7 & 95 & 31.7 & 147 & 32.7 & 0.381 \\
\hline College/university & 16 & 10.6 & 23 & 7.6 & 39 & 8.6 & \\
\hline \multicolumn{8}{|c|}{ Occupational status } \\
\hline Non-employed & 54 & 36.0 & 90 & 30.0 & 144 & 32.0 & \\
\hline Self-employed & 92 & 61.3 & 206 & 68.7 & 298 & 66.2 & 0.230 \\
\hline Employed & 4 & 2.7 & 4 & 1.3 & 8 & 1.8 & \\
\hline \multicolumn{8}{|l|}{ Marital status } \\
\hline Not married & 25 & 16.7 & 72 & 24.0 & 97 & 21.6 & \\
\hline Married & 125 & 83.3 & 228 & 76.0 & 353 & 78.4 & 0.075 \\
\hline
\end{tabular}

\section{Obstetric Characteristics Of Participants}


As indicated in Table 2 below, Findings showed that majority of the participants had 2-4 pregnancies and deliveries. Moreover only $29.2 \%(n=56)$ in the Intervention group and $70.8 \%(n=136)$ in the control group started their first Antenatal visit between 1-12 weeks as recommended. The minimum age of the respondent being pregnant at first was 14 years and maximum was 38 years with their mean age and standard deviation being 20 years (3.4). Of all the respondent $90.7 \%(n=136)$ in the intervention group and $76.0 \%(n=228)$ in the control group had four or more ANC visits as recommended with $(p<0.001)$

Table 2

Obstetric characteristics of participants $N=450$

\begin{tabular}{|c|c|c|c|c|c|c|c|c|}
\hline \multicolumn{2}{|l|}{ Variable } & \multicolumn{2}{|c|}{ Intervention } & \multicolumn{2}{|c|}{ Control } & \multicolumn{2}{|c|}{ Total/out of 450} & \multirow[t]{2}{*}{ p-value } \\
\hline & & $\mathrm{n}$ & $\%$ & $\mathrm{n}$ & $\%$ & $\mathrm{n}$ & $\%$ & \\
\hline \multirow[t]{3}{*}{ Gravidity } & 1 & 33 & 22.0 & 64 & 21.3 & 97 & 21.6 & \multirow[t]{3}{*}{0.910} \\
\hline & $2-4$ & 109 & 72.7 & 217 & 72.3 & 326 & 72.4 & \\
\hline & $\geq 5$ & 8 & 5.3 & 19 & 6.4 & 27 & 6.0 & \\
\hline \multirow[t]{3}{*}{ Parity } & 1 & 37 & 24.7 & 84 & 28.0 & 121 & 26.9 & \multirow[t]{3}{*}{0.689} \\
\hline & $2-4$ & 107 & 71.3 & 202 & 67.3 & 309 & 68.7 & \\
\hline & $\geq 5$ & 6 & 4.0 & 14 & 4.7 & 20 & 4.4 & \\
\hline \multicolumn{8}{|c|}{ Gestation age at delivery in weeks } & \multirow[t]{4}{*}{0.289} \\
\hline$<37$ weeks & & 17 & 11.3 & 38 & 12.7 & 55 & 12.2 & \\
\hline $37-40$ wee & & 116 & 77.4 & 241 & 80.3 & 357 & 79.4 & \\
\hline$\geq 40$ week & & 17 & 11.3 & 21 & 7.0 & 38 & 8.4 & \\
\hline \multirow{2}{*}{\multicolumn{2}{|c|}{$\begin{array}{l}\text { Gestation age at first visit in weeks } \\
1-12 \text { weeks } \\
13-20 \text { weeks }\end{array}$}} & 56 & 37.3 & 136 & 45.3 & 192 & 42.7 & \multirow[t]{2}{*}{0.106} \\
\hline & & 94 & 62.7 & 164 & 54.7 & 258 & 57.3 & \\
\hline \multirow{3}{*}{\multicolumn{2}{|c|}{$\begin{array}{l}\text { Age at first pregnancy in years } \\
<20 \mathrm{yrs} \\
20-34 \mathrm{yrs} \\
\geq 35 \mathrm{yrs}\end{array}$}} & 58 & 38.7 & 156 & 52.0 & 214 & 47.4 & \multirow[t]{3}{*}{0.005} \\
\hline & & 90 & 60.0 & 143 & 47.7 & 234 & 52.0 & \\
\hline & & 2 & 1.3 & 1 & 0.3 & 3 & 0.6 & \\
\hline \multirow{2}{*}{\multicolumn{2}{|c|}{$\begin{array}{l}\text { Total number of antenatal care visits } \\
1-3 \text { visits } \\
\geq 4 \text { visits }\end{array}$}} & 14 & 9.3 & 72 & 24.0 & 86 & 19.1 & \multirow[t]{2}{*}{0.000} \\
\hline & & 136 & 90.7 & 228 & 76.0 & 364 & 80.9 & \\
\hline
\end{tabular}




\section{ANC Service Utilization}

\section{Overall score on antenatal care service utilization of the study participants}

Overall ANC service utilization score in the post test was found to be $77.3 \%$ in the intervention against $57.7 \%$ in the control group. On ANC service utilization individual scoring three of the basic components (Attended by skilled health personnel, 4 or more visit during pregnancy and appropriate contents/services), those who fulfill all the three components were classified as received adequate ANC while those who did not comply the three criteria were termed as received inadequate care

Table 3

Overall score on antenatal service utilization of the study participants $n=450$

\begin{tabular}{|lll|}
\hline Score & Control & Intervention \\
\hline$=3$ (Received adequate services) & $173(57.7)$ & $116(77.3)$ \\
\hline$<3$ (Received Inadequate services) & $127(42.3)$ & $34(22.7)$ \\
\hline Total & 300 & 150 \\
\hline
\end{tabular}

Mean score on ANC service utilization between control and intervention group

Comparison between Intervention group and Control group in the post test on ANC utilization showed significant different in mean scores with $(M=2.77, S D 0.420)$ in the intervention group against $(M=2.58$, $\mathrm{SD}=0.495)$ in the control with $(\mathrm{t}=4.172, \mathrm{P}<0.01)$ at $95 \% \mathrm{Cl}$.

Table 4

Mean score on Antenatal service utilization between Intervention and control groups $(n=450)$

$\begin{array}{lll}\text { VARIABLE POST-TEST Cl } 95 \% & \end{array}$

Intervention

M

ANC SERVICE UTILZATION

SD

Control

t-value P-value

Other Factors related to the effect of interactive messaging alert system on ANC utilization

Some of the factors which showed significant relationship with ANC service utilization apart from the intervention were age $(X 2=20.338 a, p<0.01)$, Education level $(X 2=13.360 a, p<0.05)$, and Parity $(X 2=$ $5.965, p=0.051)$. Other factors did not show significant relationship as shown in table below. 
Table 5

Other factors that may influence Antenatal care service utilization $N=450$

\begin{tabular}{|c|c|c|c|c|c|}
\hline \multirow[t]{2}{*}{ VARIABLE } & \multicolumn{2}{|c|}{$\begin{array}{l}\text { RECEIVED ADEQUATE } \\
\text { SERVICES }\end{array}$} & \multicolumn{2}{|c|}{$\begin{array}{l}\text { RECEIVED INADEQUATE } \\
\text { SERVICE }\end{array}$} & \multirow{2}{*}{$\begin{array}{l}x^{2} \\
\text { P- } \\
\text { VALUE }\end{array}$} \\
\hline & $\mathrm{n}$ & $\%$ & $\mathrm{n}$ & $\%$ & \\
\hline AGE & 31 & 43.7 & 40 & 56.3 & $20.338^{a}$ \\
\hline$<20$ yrs & 234 & 70.1 & 100 & 29.9 & 0.000 \\
\hline $20-34$ yrs & 24 & 53.3 & 21 & 46.7 & \\
\hline \multicolumn{6}{|l|}{$\geq 35$ yrs } \\
\hline EDUCATION LEVEL & 155 & 58.7 & 109 & 41.3 & $13.360^{\mathrm{a}}$ \\
\hline Primary school & 100 & 68.0 & 47 & 32.0 & 0.001 \\
\hline Secondary school & 34 & 87.2 & 5 & 12.8 & \\
\hline \multicolumn{6}{|l|}{ College/university } \\
\hline $\begin{array}{l}\text { OCCUPATIONAL } \\
\text { STATUS }\end{array}$ & 94 & 65.3 & 50 & 34.7 & $0.557^{a}$ \\
\hline Non-employed & 189 & 63.4 & 109 & 36.6 & 0.757 \\
\hline Self-employed & 6 & 75.0 & 2 & 25.0 & \\
\hline \multicolumn{6}{|l|}{ Employed } \\
\hline MARITAL STATUS & 58 & 59.8 & 39 & 40.2 & $1.055^{\mathrm{a}}$ \\
\hline Not married & 231 & 65.4 & 122 & 34.6 & 0.304 \\
\hline \multicolumn{6}{|l|}{ Married } \\
\hline GRAVIDITY & 105 & 61.0 & 67 & 39.0 & $3.640^{\mathrm{a}}$ \\
\hline 1 & 168 & 67.7 & 80 & 32.3 & 0.162 \\
\hline $2-4$ & 16 & 53.3 & 14 & 46.7 & \\
\hline \multicolumn{6}{|l|}{$\geq 5$} \\
\hline PARITY & 114 & 58.8 & 80 & 41.2 & $5.965^{\mathrm{a}}$ \\
\hline 1 & 162 & 69.5 & 71 & 30.5 & 0.051 \\
\hline $2-4$ & 13 & 56.5 & 10 & 43.5 & \\
\hline$\geq 5$ & & & & & \\
\hline
\end{tabular}

The effect of Mobile health and other factors on ANC utilization 
The effect of Interactive mobile health system and other factors on ANC utilization in the study participants are shown in the table below. Logistic regression, were employed. Findings indicate that the association between mobile health and ANC utilization was (AOR $=2.164, \mathrm{P}<0.05,95 \% \mathrm{Cl}=1.351-3.466)$ when adjusted for other factors. So participants in the intervention group were 2 times more likely to utilize ANC services than the control group. Other factors which showed association includes age category of $20-34$ years $(A O R=1.877, P<0.05,95 \% \mathrm{Cl}=1.015-3.469)$, Education status at college/university level $(A O R=4.105, P<0.05,95 \% \mathrm{Cl}=1.479-11.390)$, Other factors did not show any significant association with ANC utilization as shown in Table 6 below .

Table 6

The effect of Mobile health and other factors on ANC utilization

\begin{tabular}{|c|c|c|c|c|c|c|c|c|}
\hline \multirow[t]{2}{*}{ VARIABLE } & \multirow[t]{2}{*}{ OR } & \multirow{2}{*}{$\begin{array}{l}\text { P- } \\
\text { VALUE }\end{array}$} & \multicolumn{2}{|c|}{ Cl 95\% } & \multirow[t]{2}{*}{ AOR } & \multirow{2}{*}{$\begin{array}{l}\text { P- } \\
\text { VALUE }\end{array}$} & \multicolumn{2}{|c|}{$\mathrm{Cl} 95 \%$} \\
\hline & & & Low & Upp. & & & Low & Upp \\
\hline GROUPS & 2.505 & 0.000 & 1.604 & 3.911 & 2.164 & 0.001 & 1.351 & 3.466 \\
\hline Intervention & 1.362 & 0.008 & & & & & & \\
\hline \multicolumn{9}{|l|}{ Control(Ref.) } \\
\hline Age & 0.775 & 0.287 & 1.788 & 5.100 & 1.877 & 0.045 & 1.015 & 3.469 \\
\hline$<20$ years (Ref.) & 3.019 & 0.000 & 0.696 & 3.123 & 0.896 & 0.814 & 0.359 & 2.238 \\
\hline $20-34$ years & 1.475 & 0.310 & & & & & & \\
\hline \multicolumn{9}{|l|}{$\geq 35$ years } \\
\hline Education level & 1.422 & 0.005 & 0.979 & 2.287 & 1.358 & 0.195 & 0.855 & 2.157 \\
\hline Primary school & 1.496 & 0.063 & 1.812 & 12.617 & 4.105 & 0.007 & 1.479 & 11.390 \\
\hline Secondary school & 4.782 & 0.002 & & & & & & \\
\hline \multicolumn{9}{|l|}{ College/university } \\
\hline PARITY & 1.425 & 0.015 & 1.074 & 2.387 & 1.354 & 0.235 & 0.821 & 2.233 \\
\hline 1 (Ref.) & 1.601 & 0.021 & 0.381 & 2.183 & 1.304 & 0.611 & 0.469 & 3.627 \\
\hline $2-4$ & 0.912 & 0.837 & & & & & & \\
\hline$\geq 5$ & & & & & & & & \\
\hline
\end{tabular}

\section{Discussion}

Finding in the current study observed low number of pregnant women who started their first ANC visit within the first trimester as recommended. This finding mirrors that in the TDHS of 2015/2016 report which found only $24 \%$ of pregnant women started ANC in the first trimester. First ANC visit at first 
trimester is encouraged and recommended for earlier identification of pregnant related complication and for frequent and proper management and follow up. Also $90.7 \%$ of the participants in the intervention group and $76.0 \%$ in the control group had four or more visits. This is a bit different with that in the TDHS $2015 / 2016$ of $51 \%$ as recommended (7).

These differences could be contributed by the criteria used in the enrolment of the study participant in the current study, in which only pregnant women who started ANC visit below 20 weeks were taken. It could also be due to the remainder text messages sent to pregnant women in the intervention group about their next visit.

So general the overall ANC service utilization score in the post test was found to be $77.3 \%$ in the intervention group and $57.7 \%$ in the control group based on the criteria used (Attended by skilled health personnel, 4 or more visit during pregnancy and appropriate contents/services), Those who fulfill all the three components were classified as received adequate ANC while those who did not comply the three criteria were termed as received inadequate care. The findings are supported by the study which was done in Ghana on mobile health technology in improving maternal and child health service utilization ,which also found the technology to be effective (16)

The above findings also matches with those found by (17) the study done in Zanzibar on the effect of SMS on skilled delivery and access to emergency health care which of which they found ANC utilization improved by $91 \%$. This proves that mobile health system promote ANC utilization as compared to the tradition ANC services offered in our health facilities.

In addition to that the researcher also did compare the proportional between the two group and also independent t-test was used compared their mean score differences and the results showed a significant different in the ANC service utilization between the intervention and control group. So it was evident that participants in the intervention group utilized more ANC services as compared to the control group. This finding is supported by the study done in South Africa on Interactive mobile messaging programme to promote safe motherhood and improve pregnancy outcome by (18) who observed a significant increase in utilization of ANC services to the participants of that program.

The researcher did also a logistic regression on the effect of interactive mobile technology on ANC service utilization and found a positive association in which the intervention groups were two times more likely to utilize ANC services as compared to the control group after controlling the effect of other factors such as age and education level.

Other factors, such as education level, also had a significant effect and should be addressed. Participants with college or university education were more likely to utilize ANC service as compared to those with primary level. This might be due to their high ability to understand and interpret the text messages sent to them as it has been seen in other studies in high resource settings (19) 
The current study demonstrated that the interactive mobile health system was effective in improving antenatal care service utilization. Simple SMS mobile phones messages is a technology that can be applied to assist women and their families to seek timely and appropriate medical help for routine and emergent obstetric and newborn care.

\section{Conclusion}

The study findings have revealed that an interactive mobile technology yields better outcome to participants in the part of health education as compared to conventional antenatal care health education provided in local Dodoma Urban ANC clinics. Antenatal care service utilization was higher in the intervention group compared to the control group.

Educational level was also a significant predicator for antenatal service utilization. So it should also be addressed for better outcome of this intervention.

The high use and feedback given by the participants about the system and the messages sent to them, demonstrates that women are eager to learn more about maternal health beyond what is provided in the standard antenatal clinics. By providing pregnant women with a mechanism for accessing timely evidenced-based health information, this system has contributed in raising awareness and in improving maternal health utilization for women in the study. The use of SMS technology to disseminate health information is a promising approach in our setting to improve monitoring of pregnant women and increase maternal health care utilization

\section{Limitation Of The Study}

The most frequent encountered limitation was cellular and internet network. Which delays, timely delivery of messages was a challenge at times and registration of clients was also difficult. All the required information was recorded in a paper format and the client was later registered in the system when the cellular network was good.

Telephone maintenance was another challenge among the participants as some of them reported their phones to be out of order or stolen, which prevented the continuity flow of messages to such particular participants, and when the phone was stolen the risk of spill- over effect (information contamination) from the intervention to control group could occur, although this was taken care by selecting intervention and control group from different areas/health facilities.

Participation in the current study may have been limited due to the cost of phone service. Phone credits were not granted to participants due to financial constraints. As a result some of the participants were not able to text or call back for assistant since they could not afford buying phone vouchers. Similarly, only women with phones could participate in the study. Thus women with fewer resources may have been excluded from our sample. 


\section{Recommendation}

Based on the research findings, discussions and conclusions, the following recommendations are made:

- - Since mobile messaging programmes that provide health information messages have shown success in improving health outcome in the areas of maternal and child health, policy makers and planners in health related issues such as the Ministry of health and other stake holders, should integrate this systems in our Antenatal care clinics, this system has proved to be a potentially useful innovation in low-resourced countries, where providing comprehensive care including health education seems to be difficult due to shortage of staff.

- Mobile phones messages can help women, their families and the local health workers seek timely and appropriate medical help for obstetric and newborn emergencies by reducing the time that elapses between a health crisis and care, but its replication and sustainability will depend on strong government and private sector commitment and involvement. With the aim of reducing preventable maternal mortality and morbidity.

- Early booking for Antenatal care should be promoted at the community level for early monitoring and management of any pregnant related complication that might have future adverse outcome.

- - The ministry of health may engage the private sector in a public - private partnership to substantially lower the recurrent cost of SMS and phones calls to health related issues. The communication reduction cost is crucial in planning for expansion and ensuring sustainability of the system and will also be affordable to the participants.

- More studies are needed to test the efficacy of this intervention in rural areas in order to reach a precise conclusion. This is particular important for scaling up the intervention to other setting in the country and the region at large.

\section{List Of Abbreviations}

ANC- Antenatal care.

MMR- Maternal Mortality Ratio.

MoHCDGEC Ministry of Health Community Development Gender, Elderly and Children

TDHS- Tanzania Demographic and Health Survey.

WHO-World Health Organization.

FANC-Focused Antenatal Care

HF-Health facility

UDOM-University of Dodoma 
EMOC- Emergency Obstetric Care.

BEMOC-Basic Emergency Obstetric Care

NBS- Nation Bureau Statistics

SMS-Short Message Service

\section{Declarations}

\section{Ethics approval and consent to participate}

\section{Ethical considerations}

Permission to conduct this study, ethical clearance and a research approval letter was obtained from University of Dodoma Research and publication Office. Authorization to conduct the study in Dodoma Municipal and in the selected health facilities was obtained from Dodoma Urban District director and medical officer in charges. Human rights, privacy, and confidentiality were considered in this study. Research objectives, risk, and benefits of the study were explained well to the participants. Verbal and written consent were obtained from the participants and the questionnaires were answered voluntarily. Also, the control group was not denied their right to ANC services. They continued receiving the normal standard antenatal health education offered in the local ANC clinics.

\section{Consent for publication}

Not applicable

\section{Availability of data and materials}

The datasets used and analyzed in the current study are available from the corresponding author on reasonable request

\section{Competing interests}

The authors declare that they have no any competing interest in this study

\section{Funding}

Development of this study, development of the mobile system was sponsored by the University of Dodoma being part of its ten years anniversary since its establishment.

\section{Acknowledgements}

Heartfelt thanks to the University of Dodoma, local leaders of Dodoma Municipal and study participants for their willingness to participate and contribute to this study and the health facilities who agreed to 
host research teams during research activities.

\section{Authors' contributions}

All authors drafted the original intervention.SK and TJM supervised the intervention administration and implementation and are the principal investigators, SK also advises on the context and methodological part. AE and AL revised the manuscript critically and give their expert idea. All authors read, contributed to and approved the final manuscript

\section{References}

1. KGross K, Joanna A, Kessy F, Constanze P. Antenatal care in practice an exploratory study in antenatal care clinics in the Kilombero Valley, south-eastern Tanzania BMC Pregnancy and Childbirth Full Text. BMC Pregnancy and Childbirth; 2011.

2. World Health Organization. World Health Organization recommendations on antenatal care for a positive pregnancy experience. 2016;

3. Lassi ZS, Mansoor T, Salam RA, Das JK, Bhutta ZA. Essential pre-pregnancy and pregnancy interventions for improved maternal, newborn and child health. Reprod Health. 2014;11 Suppl 1(Suppl 1):S2.

4. Shija AE, Msovela J, Mboera LEG. Maternal health in fifty years of Tanzania independence: Challenges and opportunities of reducing maternal mortality. 2011;13(December):1-15.

5. World Health Organization. WHO Maternal mortality Fact sheet. Geneva: media centre; 2016.

6. CCBRT. Changing Lives, Changing Communitie strategies. 2013;

7. Ministry of Health Community Development Gender Elderly and Children (MoHCDGEC) [Tanzania, Mainland]. Tanzania Demographic and Health Survey and Malaria Indicator Survey (TDHS-MIS) 2015-16. Dar es Salaam, Tanzania, and Rockville, Maryland, USA; 2016.

8. Heredia-Pi IA, Servan-Mori E, Darney BG, Reyes-Morales H, Rafael Lozano. Measuring the adequacy of antenatal health care a national cross-sectional study in Mexico. Mexico: World Health Organization (WHO); 2016.

9. Ngabo F, Nguimfack J, Nwaigwe F, Mugeni C, Muhoza D, Wilson DR, et al. Designing and Implementing an Innovative SMS-based alert system (RapidSMS-MCH) to monitor pregnancy and reduce maternal and child deaths in Rwanda. Pan Afr Med J. 2012;13:31.

10. Anam Feroz, Shagufta Perveen WA. Using mHealth to Improve Usage of Antenatal Care, Postnatal Care, and Immunization A Systematic Review of the Literature Table 1. BioMed Central Ltd; 2017.

11. National Bureau of Statistics Ministry of Finance Dar es Salaam, Statistician and O of CG, President's Office, Finance E and DPZ. 2012 POPULATION AND HOUSING CENSUS Population Distribution by. 2013;

12. National Bureau of Statistics Ministry of Finance Dar es Salaam, And, Office of Chief Government Statistician Ministry of State, President Office SH and GG. Mortality and Health National. 2015; 
13. Ekirapa E, Muhumuza R, Tetui M, George A. Effect of a participatory multisectoral maternal and newborn intervention on maternal health service utilization and newborn care practices a quasiexperimental study in three rural Ugandan districts. Rural Uganda: Global Health action; 2017.

14. Jhpiego. birth preparedness. 2004;

15. Division P, Health M, Era N, International ICF. Nepal. 2011;

16. Laar A., Bekyierriya E, Isang S, Baguune B. Assessment of mobile health technology for maternal and child health services in rural Upper West Region of Ghana - ScienceDirect. Ghana: Elsevier Inc.; 2018.

17. Lund S, Hemed M, Nielsen BB, Said A, Sadick K, Makungu MH R V. Mobile phones as a health communication tool to improve skilled attendance at delivery in Zanzibar a cluster-randomised controlled trial. Zanzibar: PubMed; 2012.

18. Xiong K, Kamunyori J, Sebidi J. The MomConnect helpdesk: How an interactive mobile messaging programme is used by mothers in South Africa. BMJ Glob Heal. 2018;

19. Gazmararian. Factors related to the enrolment process and reception of health tips via SMS in pregnant. Health Educ J. 2014;

\section{Figures}




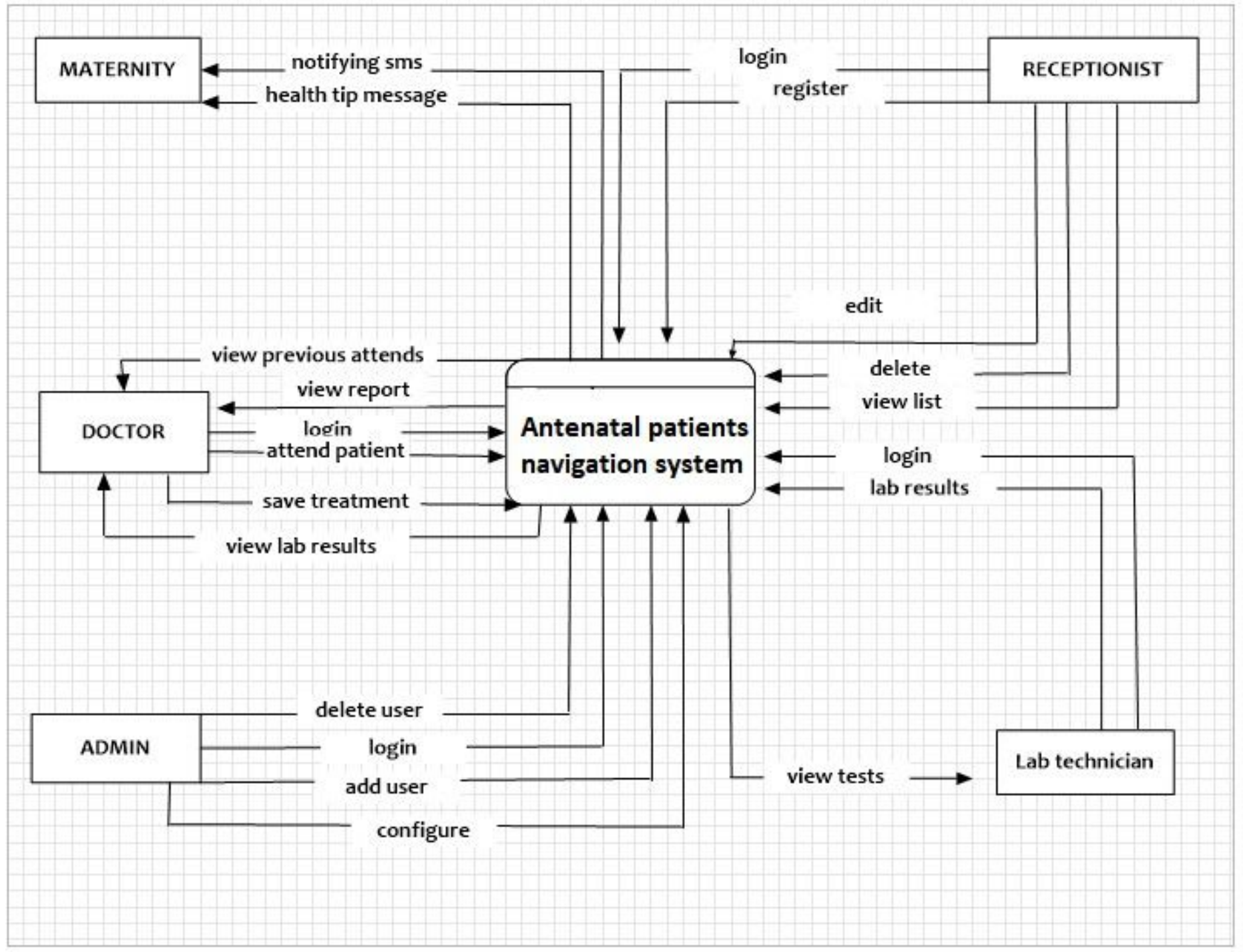

Figure 1

The flow chart diagram which depict the flow of data and information in and outside the system 